\title{
Role of Business Management into the Success and Survival of Small Businesses: The Case of Star Learning Centre in Botswana
}

\author{
Fridah Muriungi Mwobobia \\ Limkokwing University of Creative Technology- Botswana \\ Business \& Globalization Faculty \\ P.O. Box 10313, Gaborone \\ Tel: +267-722-596-82Ｅ-mail :joyfredahmuriungi@yahoo.com
}

Received: October 14, 2011

Accepted: November 4, 2011 Published: January 5, 2012

doi:10.5430/ijba.v3n1p93

URL: http://dx.doi.org/10.5430/ijba.v3n1p93

\begin{abstract}
The study aimed to establish the aspects of management, which have led to the survival, and success of the small-scale businesses in Botswana- a case of Star Learning Centre. The questions explored were 1) What is the role of management in the survival or success of Star Learning Centre? 2) What management styles, systems and practices are appropriate for Star Learning Centre and other small scale businesses in the Botswana? 3) What work culture is appropriate for business success? 4) What factors have enabled the Star Learning Centre to succeed? The study used a convenience sample comprising 31 staff members of Star Learning Centre. The probability sampling approach was applied because the number sampled was known. Questionnaires, observation and interview methods were used as the main instruments. Findings revealed that Star Learning Centre success can be attributed to effective management, team work, timely communication, conducive working environment. The problems/challenges faced by the Centre were: shortage of capital, shortage of land, lack of open discussion between staff and management, and an unsatisfactory remuneration system. The study recommends further research that may capture more and bigger businesses.
\end{abstract}

Keywords: Management, Business Success/ Survival, Organizational Culture, Teamwork, Communication

\section{Introduction}

\subsection{Background to Study}

Small and Medium Enterprises (SMMEs) play a significant role in sustainable socio-economic of a country in terms of contribution to GDP, job creation, generation of wealth, poverty alleviation , capacity building and uplifting the welfare of the people through provision of goods and services including education. In Botswana it is estimated the SMME sector's contribution to be in the range of 30-45\% of GDP (LEA 2007).

The Star Learning Centre is an English Medium Christian Primary School situated in about six kilometres east of the City of Gaborone in Botswana. Its catchment area is Gaborone and the surrounding villages and settlements. Established in 1992 with only 51 learners and 4 teachers, today after 13 years it has grown tremendously, with 600 learners and 78 members of staff.

The Centre has continually performed exceptionally well since its inception in 1992, and has satisfied its customers by offering favorable fees payment structure, wide range of quality services, and outstanding Primary School Leaving Examination (PSLE) results. For instance its PSLE pass rate over the past three years was 92\%, 94\% and 95\% respectively. The Centre is managed by a Managing Director, a Headmaster and Deputy.

\subsection{Statement of the Problem}

Why is Star Learning Centre succeeding while many government supported small businesses are failing? Is poor management the fundamental cause of the unsatisfactory state of SMMEs in Botswana? To (Cronje, Toit Du and Motlala 2000) one of the commonest causes of failure in any business, particularly a small one, is poor management. Motlhatlhedi (2001) adds that, although finance is perceived as the major problem facing SMMEs in Botswana, the quality of their products is also a matter for concern. 
There are many reasons why Star Learning centre is succeeding and challenges that it is facing. In examining different theories and reasons why Star Learning Centre has succeeded, no set standard that can be applied. Could good management , motivated employees, adequate funds be the reasons? This study also seeks to identify the work culture at Star, and problems facing Star.

\subsection{Objectives of the Study}

The purpose of this study is to investigate the role of management in the success and survival of Star Learning Centre while the counterparts who even have government support are failing.

The challenges and the problems faced by small businesses in particular Star Learning Centre.

Specifically, the objective of the study is to:

To explore the role of management at the Star Learning Centre

To examine management styles, systems and practices

To examine other factors that have contributed to the Star Learning Centre success

To examine the work culture of the Star Learning Centre

To recommend the most appropriate action plan that could be adopted to ensure that the Star Learning Centre and other similar institutions remain sustainable and increase their competitiveness and profitability

\subsection{Research Questions}

This study attempts to answer the following questions:

i) What is the role of management in the survival or success of Star Learning Centre?

ii) What management styles, systems and practices are appropriate for Star Learning Centre and other small scale businesses in the Botswana?

iii) What work culture is appropriate for business success?

iv) What factors have enabled the Star Learning Centre to succeed?

v) What can be recommended for Star Learning Centre for future?

\section{Significance of Study}

The study will provide the role the management plays to the success and survival of small businesses and a list of factors that contributes to the success of a small business.

Lessons learnt here will be used to highlight on areas of improvement for Star Learning Centre and other small scale businesses in Botswana in order to enable them to effectively cope with challenges of organizational change and development. The study is a humble contribution to the body of knowledge regarding the management of small-scale businesses in Botswana and other third World countries experiencing similar challenges.

\section{Research Methodology}

\subsection{Research Design}

The present study adopted a mixture of approaches, incorporating both positivism and phenomenology research paradigms. The triangulation approach was adopted due to the nature of the sample studied. The sample involved teaching staff and management team. Data was also obtained from other stakeholders such as office and auxiliary staff. The use of multiple research methods ensured the reliability and validity of the results. Both approaches involved theory-building as well as some theory-testing aspects (Hussey and Hussey 1997).

\subsubsection{Population and sample}

The population of the study comprised the management and non-management staff such as teachers, cleaners and office staff of the Star Learning Centre, which totaled 78 respondents.

The source of study sample was the Star Learning Centre Staff Register as per the 2003 records. The probability sampling approach was applied because the number sampled was known.

\subsubsection{Instrumentation}

Care was taken to ensure that questionnaire questions were structured in such a way that similar or familiar questions started, followed by orientation, content and personal items were placed at the end and were worded carefully to avoid offending the respondents. 
After the questionnaire was pilot surveyed, and necessary corrections made, it was run into thirty nine (39) copies and a cover letter was stapled on each. The thirty nine (39) copies were then divided into three categories (as per the sample groups), enveloped and addressed according to the group they belonged to, for example teaching staff.

To obtain the most truthful feedback and to encourage better responses, participants were requested to respond in anonymity.

\subsubsection{Reliability and Validity}

For reliability, test-retest technique was used. The questionnaire items were piloted while interview schedule items were pre-tested and necessary amendments were made in order to maximize returns and minimize the error rate. The questionnaire was piloted on small a sample. Three copies of the questionnaire were sent to Star Learning Centre and three respondents (each from one group) answered. The interview questions were pre-tested on my colleague. This was done twice on two different occasions in order to obtain a correlation between the two sets of responses.

With regard to scientific validity, the research was carried in a manner that ensured its academic integrity and scientific validity: there was no fabrication or plagiarism. Care was also taken when choosing participants; no force was used.

Face and content validity were used the researcher asked friends, colleagues and individuals from target population to comment on the relevance, balance and adequacy of the research instrument in relation to the research objectives. The opinion of the experts in the field of management was also sought in regard to adequacy of the research instruments.

\subsection{Data Analysis and Results}

Since the research design combined the qualitative and quantitative paradigms data was analyzed qualitatively and quantitatively.

Quantitative data from the closed questionnaire items was statistically analyzed and presented using descriptive methods, such as tables for easier crosschecking and comparison with the qualitative data.

The data was initially classified in various categories, as (Saunders, Lewis and Thorn 2000) note quantitative data can be divided into distinct categories. The data was then classified into two sets: categorical and quantifiable data.

Categorical data was further divided into nominal and ordinal measures. The nominal measure involved the descriptive data that indicated alternative states of variables for, example, either male or female.

Ordinal measures were ranked estimates usually reflecting either choices made by the subject or categories determined by the researcher.

This involved interval and ratio measures. Interval measures are variables whose attributes can be rank- ordered, for example, salary scale while ratio measures are variables based on absolute scale, which has a fixed zero point, for example age, working experience, etc (Mancosa Research Methods Module, 2001).

After classifying data into categorical data such as gender and quantifiable data such as age, number of years worked among others, data was then presented and analyzed in the form of tables, graphs and frequencies:

- To show specific values such as age, frequency distribution was used

- A bar chart was used to show the different methods of communication

- Trend a line graph was used in which data values for each period (PSLE) results was joined by a line.

- A pie chart was drawn to represent proportions. This was used to analyse the Star Learning Centre team membership. First percentages were calculated and then converted into degrees.

Having drawn the graphs, charts and tables further analysis was done which encompassed describing, interpreting, cross referencing and comparing variables.

Conclusions were drawn from the results, which were generalized to cater for the whole population.

The qualitative data from the interview was de-textualized by converting the extended texts into more manageable forms such as summaries, charts and diagrams. The research applied the deduction position

\section{Findings and Discussions}

Thirty (30) out of thirty nine (39) questionnaires were responded to reflecting a total of $77 \%$ response. The order of presentation is based on the six variables used in the questionnaire: organizational staff, resources, teamwork, communication, management and culture. 


\subsection{Length of Service at Star Learning Centre}

From the findings, 47\% (Table 1.) of the Star Learning Centre staff had served 5 years and above, 27\% had served between 3-4 years, 16\% 1-2 years and 10\% represented staff members who had served for less than 1 year. The manager (who was the only one interviewed because of her status and vast knowledge of the Star Learning Centre and other similar businesses) indicated that there was a low rate of staff turnover for only 0 to 1 employees left the Centre annually on the expiry of their contracts. The application of good human resource management practices at the Centre, coupled with satisfactory working conditions and remuneration, as well as good interpersonal relations, among others, seem to have contributed greatly to the favourable situation the Centre enjoys. In order to retain employees and reduce turnover managers must meet the goals of employees without losing sight of the organization's goals, thereby creating a "win-win" situation (http://Employee_retention).

\subsection{Staff Orientation}

According to the findings, $97 \%$ ( Figure 1.) of the respondents said that they were given orientation when they joined the Star Learning Centre; 3\% of the respondents indicated the contrary. The manager, also acknowledged that orientation was an on - going exercise in the Star Learning Centre. Orientation is key to business survival because employees get to know the organization's expectations, rules and regulations, policies and procedures that act as a guide to their performance.

\subsection{Uniting factor among Star Learning Centre Staff}

Findings revealed that, $63 \%$ ( Figure 2.) of the respondents reported that the greatest uniting factor among Star Learning Centre staff is teamwork, $30 \%$ said it is daily morning mass in the school chapel and $7 \%$ cited accountability as the greatest uniting factor.

\subsection{On-the-Job Training}

From the findings, 97\% (Figure 3.) of the respondents indicated that they had received on-the-job training since they joined the Star Learning Centre. Only 3\% of the respondents reported not having undergone any on-the-job training since joining Star Learning Centre. The manager also acknowledged the existence of the on-the-job training at the Centre, which is conducted mostly through school based workshops. In addition to orientation, other training activities at Star Learning Centre have often included in- house workshops where staff watch video presentations in areas such as teaching skills, counselling, time management, etc. These sort of training activities are good because employees acquire vital skills, knowledge and attitudes (Borrington and Stimpson 2000). This is a sort of employee empowerment. To (Shekari, Rabiee,Afshari and Ahanim 2011) empowerment is a guidance of advancement and organizational prosperity.

\subsection{Further Training}

According to the findings, 93\% (Figure 4. \& Table 2. ) of the respondents indicated that Star Learning Centre management encourages the staff to pursue further studies, $7 \%$ indicated the contrary. On-the-job training has the potential of leading to improved performance, greater motivation and commitment of the employees. Empowering employees should be one of the most important tasks of organization in competitive benefits and its living (Shekari et al 2011).

\subsection{Staff Discipline}

From the findings, $80 \%$ (Table 3.) of the respondents acknowledged that there is excellent discipline among Star Learning Centre staff, while 20\% recorded discipline as good. Interview findings ranked Star Learning Centre staff as being very good in terms of discipline. Through observation, staff discipline in terms of punctuality was noted to be high. Employees can only be disciplined when their needs are fulfilled and their working conditions are conducive to high performance. According to (Borrington et al 2002:) this is in accord with McGregor's Theory Y, which states that if employees are given the right conditions, they will enjoy work, be creative, productive and will work willingly for the business.

\subsection{Source of Satisfaction to employees of Star Learning Centre}

According to the findings, 57\% (Figure 5.) of the respondents indicated the source of satisfaction for Star Learning Centre employees as being good working conditions, $40 \%$ good management approach and $3 \%$ the success of the organization and diversity among the staff. The manager said that the Centre's employees could also be deriving joy and motivation from other fringe benefits provided by the management such as free 10 o'clock tea, house allowance and some school organized trips. The manager also added that promotion, which is given to the outstanding employees, is a morale booster. 


\subsection{Resources}

\subsubsection{Control of Materials}

About 93.3\% (Figure 6.) of the respondents reported that the material usage in the Star Learning Centre is controlled by staff signing for them at the supplies office, 3.3\% of the respondents reported that it is bought when required and another $3.3 \%$ of the respondents did not give any responses. This revealed that there is effective control of usage of materials such as stationery, books, toiletries, etc, at Star Learning Centre This indicates that there is effective application of one of the management processes of control whose objective is to create a sense of responsibility and accountability, thereby minimising resource wastage, hence less operational costs, ensuring organisational profitability and survival.

\subsubsection{Centre’s Suppliers}

The manager said the Centre has various suppliers for various items, (Table 4.) for instance, Salama Pty Ltd Co. supplies stationery, and Metsef Wholesalers supplies stock for the school tuck shop, Sahara Computers supplies and maintains the school computers. The Centre has established a long term business relationship with all the suppliers.

\subsubsection{Rating of Management of Resources}

According to the findings, $60 \%$ (Figure 7.) of the respondents indicated that the best managed resource are people, $33 \%$ of the respondents said time, and 17\% materials and 7\% finance. In this question 5 respondents gave each two answers. The manager also accepted that the Centre's employees are ranked as very good as far as their work is concerned. This is in agreement with (Beardwell and Holden 2001) who emphasize that today's companies should treat employees as a resource rather than an expense and should view expenditure on training as an investment rather than a cost. That will be the only way to succeed in the cutthroat business competition.

\subsection{Teamwork}

With regard to teamwork, the findings show that the concept of managing through teams is widely practiced at the Centre. An overwhelming 80\% (as shown in Figure 9.) of Star Learning Centre staff belong to at least one team. Teamwork in the organisation brings a sense of shared ownership of work and responsibilities, which makes it easier for the management to coordinate activities. Since teamwork allows for greater participation and increased performance, it ultimately results in higher employee motivation and satisfaction, which in turn results in higher productivity.

\subsection{Communication}

\subsubsection{Common Methods of Communication in Star Learning Centre}

According to the findings $73 \%$ (Figure 11.) of the respondents, cited the memorandum as the most commonly used method of communication at the Star Learning Centre, 23\% of the respondents said briefings and $4 \%$ cited memorandum and briefings. Communication in every organization is central to success. Briefings and meetings are the other communication methods used by the Star Learning Centre management. Like memos, these are also good in aiding business communication and survival. Their strength lies in their ability to give opportunity for immediate response.

\subsection{Management}

Findings revealed that, $86 \%$ (Table 7.) of the respondents indicated that the management approach used in the Star Learning Centre was inspirational; and 7\% that of leading; and 7\% directional. None indicated that the approach was that of commanding. Star Learning Centre management's ability to inspire people to voluntarily and enthusiastically work towards the attainment of the Centre's goals has been central to the success of the organization. This Agrees with (Du Toit, Erasmus and Strydom 2010).

Findings shown that, 93\% (Table 8.) of the respondents acknowledged that Star management has taught them responsibility, while $7 \%$, cited openness. The Centre's manager explained that management tries to raise employees` levels of responsibility through the tasks allocated to teams. She said this encourages creativity and accountability. Responsibility was rated the most outstanding principle acquired by the Star Learning Centre staff from management. Responsibility and accountability are closely linked and when employees are made to account for their actions or results they tend to become responsible in everything they do. The responsibility aspect at the Star Learning Centre should be seen in the light of other effective management processes, such as resources control, teamwork and staff training, all of which can be attributed to its business success.

\subsubsection{Other Factors That Have Contributed to the Success of Star Learning Centre}

Findings revealed that, 80\% (Figure 13.) of the respondents cited the success of Star as largely being attributed to effective management, $13.3 \%$ recorded good working conditions, 3.3\% recorded the strategic location and 3.3\% recorded good customer relations. Other factors that were stated as contributing to the success of Centre are good working conditions, 
which account for the high motivation amongst the workers as well as learners to do to their best. These working conditions range from large air conditioned and carpeted classrooms, adequate teaching/learning facilities, and cleanliness, to a quiet environment. This agrees with (Dransfield and Needham 2001) who emphasize that the environment in which an employee works is very important and makes people feel good about their work. This can lead to better performance.

\subsection{The Most Outstanding Strength of the Star Learning Centre}

According to the findings, $86 \%$ (Figure 14.) of the respondents cited that good management and highly trained staff as the most outstanding strengths of Star Learning Centre; 7\% cited good working capital and locality; and 7\% cited legality and modern facilities. It is apparent that the location of the Centre has contributed to its success. For the nature of its business, one might argue that the Centre is strategically located six kilometres away from the City. The location offers a conducive learning environment and is convenient for driving during peak hours for there is less traffic congestion on the road. Moreover, the Centre is located in a large residential estate; a good catchment area as most learners live nearby.

\subsection{Organizational Culture}

\subsubsection{Culture of Work at Star Learning Centre}

A large number of the respondents (97\%) (Figure 15.) recorded that there is a culture of teamwork at Star Learning Centre and 3\% indicated the opposite. The manager confirmed the centre's culture of work, as that of teamwork, achievement and hard work. She explained that values such as: good moral conduct, hard work, teamwork, good customer service, achievement among others, which are observed by all staff, forms part of the Centre's culture.

\subsection{Star Learning Centre PSLE Results Trend}

The Centre's manager acknowledged (Figure 16.) that the most outstanding achievement of the Star Learning Centre are the Primary School Leaving Examination results which were recorded as 92\% in 2000, 94\% in 2001, 91\% in 2002 and 95\% in 2003 pass. Such impressive results are a good marketing tool of the organisation. This can be regarded as a great achievement for the organization, and is only possible with a combination of factors such as high staff motivation, staff discipline, and the presence of a highly qualified and experienced workforce.

One of the challenges facing the Centre at the moment according to the manager is severe shortage of land to expand and develop sporting fields. Staff turnover is minimal, 0-1 employees leave Star annually due to contracts ending.

\subsection{Respondents Suggestions for Improvement at Star Learning Centre}

Respondents gave the following suggestions:

A good number of the respondents (47\%) suggested that Star Learning Centre should acquire more land in order to expand the school so as to meet high demand, have secondary level and enough sporting fields. This was also cited by the manager as a way forward by the Centre's management.

$17 \%$ of the respondents suggested staff salaries, allowances and gratuities should be increased in order to retain staff, 3.3\% of the respondents suggested that Star Learning Centre management should motivate staff more.

A small number of the respondents (7\%) suggested that a foreign language should be introduced in order to widen learners` choice and the school should engage in more extra curricular activities.

$27 \%$ of the respondents suggested that, there should be more open discussions between Star management and staff, 3.3\% of the respondents suggested permanent teachers should be employed although $0-1$ teachers leave annually due to contracts ending.

$3.3 \%$ of the respondents suggested that more in-service training should be provided to the staff. The manager also suggested that, the way forward for Star was to continue developing staff and learners for better performance in terms of PSLE results and general customer service.

Another 3.3\% suggested that more fringe benefits should be provided to the staff and another 3.3\% suggested that Star should trust the Lord for guidance. Some of the respondents did not give any suggestions.

\section{Conclusion}

From the research findings the study has established the following as management aspects which have been central to the survival of the Star Learning Centre: they include good human resources management activities and functions of staff orientation, retention, on-the-job training, staff relations, staff motivation, good working conditions and good pay among others. 
The Star Learning Centre management has played a very critical role in ensuring its success and survival. Among the notable management processes include: proper strategic planning, which involves top management setting goals and formulating the mission and vision of the organization for direction.

The management practices, which are noted to be key to business survival, are good organizing and coordinating skills; teamwork and a well established resource control and monitoring system.

Appropriate management styles of inspiring employees through support, encouragement and motivation, good communication, and a task oriented organizational culture have contributed a great deal to making the business competitive and successful. In addition, factors such as mature and highly qualified staff, strategic location of a business and good working capital have contributed to Star Learning Centre business survival.

Although the common causes of business failure, such as shortage of skills and capital, were not found to be among constraints facing the Star Learning Centre, the Centre is facing the problem of land shortage, lack of open discussion between staff and management, and an unsatisfactory remuneration system.

\subsection{Recommendation for Future Researchers}

Based on the findings of this research, the following suggestions are forwarded to the future researchers

A rigorous research comprising bigger sample is recommended

A study with narrower scope would be able to furnish more specific details on the topic of study

\section{References}

Ahmad,S.Z.,Xavier, S.R.,Perumal.S.,Nor., M.L.,and Mohan,C.,J . (2011).The transition from corporate Careers to business ownership: The case for women entrepreneurs in Malaysia. International Journal of Business Administration vol.2 , No.3, 2011, http://dx.doi.org/10.5430/ijba.v2n3p148

Allison, B. (1997). The student's Guide to preparing Dissertation and Theses. London: Kogan Page Limited.

Armstrong, M. (1998). Managing People. London: Kogan Page Ltd.

Beardwell, I., Holden, L. (2001). Human Resource management a contemporary approach, $3^{\text {rd }}$ Edition. United Kingdom: Financial Times. Prentice Hall.

Best, W.J,. Kahin V. J. (1992). Research in Education 6 ${ }^{\text {th }}$ Edition. New Delhi: Prentice-Hall Inc.

Bidpa, (2008) Botswana institute of Development and policy analysis profile

Bidpa (2000) Financial Assistance policy (FAP) Final report for Ministry of Finance and Developing planning (MFDP).

Bill, L. (1994). New ways to pay Employees’ HR Magazine, February. pp 61-69

Borrington, K., Stimpson, P.(2002). Business studies $2^{\text {nd }}$ Edition. London: John Murray Publishers Ltd. 50 Albennarle Street.

Botswana Review 22nd Edition (2003). B\& T Directories (Pty) Ltd. Gaborone.

Briscre, A. (1995). Small Business support in Botswana. Gaborone: Morula press for Business School of Botswana.

Carrell, M.R., Elbert, N.F., Hatfield, R.D., Grobler, P.A., Marx, M.\& Van der Schyf, S. (1999). Human Resource Management in South Africa. New Jersey:Prentice-Hall Inc.

Centre for Labour Market Studies, (2002). 'Research methods and Dissertation Guidelines Version 8. Leicester: University of Leicester.

Chang, Y.R., Curtin J. M. (1995). Succeeding as - A self managed Team. London: Kogan Page Ltd.

Cooper, D.R., Schindler, P.S.(1998). Business Research methods $6^{\text {th }}$ Edition.Boston: Irwin/McGraw Hill.

Croft, C. (1996). Time Management. London: International Thomson Business Press.

Cronje, A. Toit Du, Motlatla. (2000). Introduction to Business Management $5^{\text {th }}$ Edition.Cape Town: Oxford University press.

Daft, L.R. (2000). Organisation Theory and Design. $7^{\text {th }}$ Edition. USA: South-Western College.

Daniels, J.D., Radebaugh,L.H.(200l). International Business Environments and operations $9^{\text {th }}$ Edition. New Jersey: Prentice-Hall Inc. Upper Saddle River. 
Drafke W.M., Kossen S. (1998). The Human side of organizations $7^{\text {th }}$ Edition. USA:Longman Inc.

Dransfield,R.,Needham, D.(200l). Business studies for you $2^{\text {nd }}$ Edition. United Kingdom: Nelson Thornes Ltd. Delta place.

Drummond, H. (2000). Introduction to organizational Behaviour. Newyork: Oxford university press.

Du Toit G.S:, Erasmus.BJ., Strydom. J.W.,(2010) Introduction to Business Management $7^{\text {th }}$ Edi: Oxford University: South Africa: ISBN 9780195766882

Dyk Van PS., Nel PS., Loedolff Van P., Haasbroek G D. (2001). Training Management $3^{\text {rd }}$ Edition. Cape Town: Oxford University press.

Fincham,R., Rhodes, P.(1999). Principles of organizational Behaviour. $3^{\text {rd }}$ Edition. United States: Oxford University Press.

Gary D., Phillip C. and Joan A., (1998)'Strategic performance model', Empowerment in organizations. Vol.6 no.2,1998. http://dx.doi.org/10.1108/14634449810210742

Gerber P.D., Nel PS., Dyk Van PS., Haasbroek G D., Schultz HB., Sono T., Werner A. (2001). Human Resources Management $5^{\text {th }}$ Edition. Cape Town: Oxford University Press Southern Africa.

Grainger, P.(1994). Managing People. USA: Nicholas Publishing Co.

Griffen, R.E., Ebert, R.J. (1989) Business. New Jersey: Prentice - Hall.

Griffin,W.R. (2003). Fundamentals of management $3^{\text {rd }}$ Edition. USA: Houghton Mifflin.

Hamilton,C., Parker,C. (1997). Communicating for Results. $5^{\text {th }}$ Edition. USA: Wadsworth Publishing Co.

Handy,C. (1991). Gods of Management. London: Business Books Limited. 20 Vauxhall Bridge Road SWIV 2SA.

Harvey, D., Brown, R.D. (200l). An experiential Approach to organization Development $6^{\text {th }}$ Edition. New Jersey: Prentice-Hall.

Holt, D. A .(1987). Basic concepts of Business Administration. London: Edward Arnold Ltd, 41 Bed Ford square.

Huse, F.E., Cummings,G.T.(1985). Organization Development and change $3^{\text {rd }}$ Edition. USA: West Publishing Co.

Hussey, J. and Hussey, R.(1997). Business Research; A practical guide for undergraduate and post graduate students. London:Macmillian.

Ivancevich, M.J., Matteson, T.M.(1999). Organizational Behaviour Management $5^{\text {th }}$ Edition.USA: Irwin/McGraw Hill.

Jackson H. J., Morgan P. C., Paolillo J.G.P. (1986). Organization Theory: A micro perspective for management. New Jersey: Prentice- Hall.

Jacob. B., Masheka.A. Morupisi.J. (2000). Religion For All. Gaborone:Macmillan Botswana Publishing Co. (Pty) Ltd.

John, S.H. Palph L. K., Raiffa, H. (1998). Harvard Business Review Vol.76 (5) p. 47-60.

Management College of Southern Africa (2001). Research Methods. Durban: South Africa.

Management College Of Southern Africa (2002). 1nternational Business. Durban: South Africa.

Ministry of Education (2000). Bareng Gaborone: Educational Publications.

Mintzberg, H. (1971). 'Managerial work: analysis and observation'. Management science, October, B 97-110.

Mlazie, D. (2003). Business and construction review , Vo1.13 (3) pp16-l7.

Moorhead,G., Griffin, W.R. (2004). Organizational Behaviour. Managing people and organizations $7^{\text {th }}$ Edition. New York: Houghton Mifflin Company.

Moses, B.M. (2001). Risk management \& Productivity. Productivity and Quality forum, December, Vol. 7(2) pp17

Motlhatlhedi, K. (2001). Productivity and Qualitv Forum, Quality improvement Taskforce for SMME products JulySeptember, Vol. 7 (1), pp7

Naylor, J. (1999). Management. London: Financial Times Pitman Publishing 128 Long Acre.

Noe, A. R. (1999) .Employee Training \& Development. USA: Irwin McGraw-Hill

Ofori D., and Aryeetey M.,(2011) Recruitment \& selection practices in small \&medium Enterprises: Persepectives from Ghana. International Journal of Business Administration. doi:10.5430/ijba.v23p45 
Republic of Botswana, (1997). National Development Plan (NDP8) 1998-2003 Gaborone: Government Printers . pp9-13

Republic of Botswana, (1998). Small, Medium and Micro Enterprise Task Force Report. Gaborone: Government printers.

Rothwell, J.W., Sullivan,R., Mclean, N.G. (1995). Practicing organization Development. USA: Jossey-Bass Pfeiffer.

Saffu,K., Walker. H and Hinson., R (2007)” An empirical study of perceived strategic value and adoption construct: The Ghanian case”. Management Decision vol. 45,no.7,2007 pp 1083-1101. Emerald Group publishing Ltd. http://dx.doi.org/10.1108/00251740710773925

Saunders, M.N.K., Lewis, P. and Thorn, A. (2000). Research methods methods for Business Students $2^{\text {nd }}$ Edition. Harlow, England: Financial Times/Prentice Hall.

Shekari H., Rabiee.A.,Afshari M and Ahanim (2011) Using effective factors in Employees Empowerment of industrial organizations with Analytical Network Approach (ANP) casestudy: Textile factories of Qom province. International Journal of Business Administration.doi:10:5430/ijba.v2n3p160

Simms, J. (1995). Communication. New York: Oxford University Press.

Taylor, R. (1995). 'Only 20 percent of managers have degrees'. Financial Times, 19 June 11.

Thompson, Arthur A. Jr. and Strickland, A.J.III. (1998). Strategic Management. Concepts and Cases. $11^{\text {th }}$ Edition. Irwin McGraw- Hill.

Usunier, J.C. (1996). Marketing across cultures. London: Prentice-Hall.

Waweru, A.S.M. (2011). Comparative analysis of competitive strategy implementation. Journal of Management \& Strategy.doi: 10.5430/jms.v2np49

Wokorach, J. B. (1997) Commerce $4^{\text {th }}$ Edition. Botswana: Salama publishers.

http://en.wikipedia.org/wiki/Management accessed on 3/04/11

http://en.wikipedia.org/wiki/Employee_retention accessed 23/10/2010

http://www.aep.wur.nl/NR/rdonlyres/D3255A0B-D9AB-4EF3-93EE-EE059BA76DAF/141023/085_Grekova.pdf accessed 13/03/2011

http://www.lea.co.bw/uploads/files/Packaged\%20BIDPA\%20Study.pdf?size=105115 accessed 12/06/2011

Table 1. Length of service at star learning centre

\begin{tabular}{|l|c|c|}
\hline Period of service in years & Number of employees & Percentage (\%) \\
\hline Less than a year & 3 & $10 \%$ \\
\hline $1-2$ & 5 & $16 \%$ \\
\hline $3-4$ & 8 & $27 \%$ \\
\hline 5 and above & 14 & $47 \%$ \\
\hline Total & 30 & $100 \%$ \\
\hline
\end{tabular}

From the findings, $47 \%$ of the Star Learning Centre staff had served 5 years and above, $27 \%$ had served between 3-4 years, 16\% 1-2 years and 10\% represented staff members who had served for less than 1 year. The manager (who was the only one interviewed because of her status and vast knowledge of the Star Learning Centre and other similar businesses) indicated that there was a low rate of staff turnover for only 0 to 1 employees left the Centre annually on the expiry of their contracts.

Table 2. Additional courses undertaken by Centre’s staff

\begin{tabular}{|l|l|}
\hline Additional Courses undertaken & Number of staff members \\
\hline Computers & 20 \\
\hline First Aid & 5 \\
\hline Marketing & 3 \\
\hline
\end{tabular}




\begin{tabular}{|l|l|}
\hline Public Relations & 3 \\
\hline HIV/AIDS & 2 \\
\hline Special Education & 2 \\
\hline Housekeeping & 1 \\
\hline Time Management & 1 \\
\hline Discipline Training & 1 \\
\hline Total & 38 \\
\hline
\end{tabular}

Findings revealed that $93 \%$ of the respondents had undertaken courses in various fields as indicated in the table above. Some had attended more than one additional course.

Table 3. Staff discipline

\begin{tabular}{|l|l|}
\hline Respondents rating & Status \\
\hline $80 \%$ & Excellent \\
\hline $20 \%$ & Good \\
\hline
\end{tabular}

From the findings, $80 \%$ of the respondents acknowledged that there is excellent discipline among Star Learning Centre staff, while $20 \%$ recorded discipline as good. Interview findings ranked Star Learning Centre staff as being very good in terms of discipline. Through observation, staff discipline in terms of punctuality was noted to be high.

Table 4. Centre’s suppliers

\begin{tabular}{|l|l|}
\hline Items & Suppliers \\
\hline Stationery & Salama (Pty) Ltd \\
\hline Stock & Metsef \\
\hline Computers & Sahara \\
\hline
\end{tabular}

The manager said the Centre has various suppliers for various items, for instance, Salama Pty Ltd Co. supplies stationery, and Metsef Wholesalers supplies stock for the school tuck shop, Sahara Computers supplies and maintains the school computers. The Centre has established a long term business relationship with all the suppliers.

Table 5. Limitation of the number of teams one can join in Star Learning Centre

\begin{tabular}{|l|l|}
\hline Respondents percentage & Their view \\
\hline $56.6 \%$ & Team membership limited \\
\hline $36.4 \%$ & Team membership not limited \\
\hline $7 \%$ & No response \\
\hline
\end{tabular}

Findings revealed that $56.6 \%$ of the respondents, indicated that there is a limit as to the number of teams/committees one can join, $36.4 \%$ of the respondents said that there is no limit, while $7 \%$ of the respondents were non-committal.

Table 6. Setting goals /objectives for the teams/committees

\begin{tabular}{|l|l|}
\hline Respondents percentage & Setting of goals \\
\hline $50 \%$ & Team members \\
\hline $50 \%$ & Management \\
\hline
\end{tabular}

Half of the respondents, that is $50 \%$ indicated that team/committee members set their own goals; $50 \%$ indicated that the Centre's management sets goals for the teams/ committees. 
Table 7. Senior managers`management styles

\begin{tabular}{|l|c|c|}
\hline Role & Number of staff members & Percentage (\%) \\
\hline Leading & 2 & $7 \%$ \\
\hline Inspirational & 26 & $86 \%$ \\
\hline Directional & 2 & $7 \%$ \\
\hline Commanding & 0 & $0 \%$ \\
\hline Total & 30 & $100 \%$ \\
\hline
\end{tabular}

Findings revealed that, $86 \%$ of the respondents indicated that the management approach used in the Star Learning Centre was inspirational; and $7 \%$ that of leading; and $7 \%$ directional. None indicated that the approach was that of commanding.

Table 8. Lessons learnt by staff from Management

\begin{tabular}{|l|l|}
\hline Percentage of respondents & Lessons learnt \\
\hline $93 \%$ & Responsibility \\
\hline $7 \%$ & Openness \\
\hline
\end{tabular}

Findings shown that, 93\% of the respondents acknowledged that Star management has taught them responsibility, while $7 \%$, cited openness. The Centre's manager explained that management tries to raise employees`levels of responsibility through the tasks allocated to teams. She said this encourages creativity and accountability.

Table 9. Age Distribution

\begin{tabular}{|l|l|l|l|l|l|}
\hline Age in Years & $20-29$ & $30-39$ & $40-49$ & $50-59$ & Total \\
\hline Number of respondents & $7(23.3 \%)$ & $15(50 \%)$ & $7(23.3 \%)$ & $1(3.3 \%)$ & $30(100 \%)$ \\
\hline
\end{tabular}

Findings show that a major group of the respondents (50\%) falls under the 30 to 39 years age group, followed by $23.3 \%$ respondents falling under the 40 to 49 years age group. Another 23.3\% of the respondents fall under the 20 to 29 years age group and $3.3 \%$ fall between ages 50years to 59 years .

Table 10. Marital Status distribution

\begin{tabular}{|l|l|l|}
\hline Single & Married & Total \\
\hline $10(33 \%)$ & $20(67 \%)$ & $30(100 \%)$ \\
\hline
\end{tabular}

As indicated in Table 10., the greater number of the respondents 67\% are married and 33\% are unmarried

Table 11. Gender distribution

\begin{tabular}{|l|l|r|}
\hline Male & Female & \multicolumn{1}{|l|}{ Total } \\
\hline $10(33 \%)$ & $20(67 \%)$ & $30 \quad(100 \%)$ \\
\hline
\end{tabular}

Findings reveal that $67 \%$ of the respondents are female , while $33 \%$ are male 
Table 12. Highest academic/professional qualifications attained

\begin{tabular}{|l|l|l|l|l|l|l|}
\hline Qualifications & Masters Degre & $\begin{array}{l}\text { Bachelor } \\
\text { Degree }\end{array}$ & Diploma & Certifica & $\begin{array}{l}\text { BGCSE or JC } \\
\text { Certificate }\end{array}$ & Total \\
\hline Number of staf 2 & $\begin{array}{l}12 \\
(6.6 \%)\end{array}$ & $\begin{array}{l}10 \\
(40 \%)\end{array}$ & $\begin{array}{l}(33.3 \%) \\
(10 \%)\end{array}$ & $\begin{array}{l}3 \\
(10 \%)\end{array}$ & 30 \\
\end{tabular}

Findings reveal that the respondents are well educated for 6.6\% hold maters degree, a greater number of respondents $40 \%$ hold first degree, $33.3 \%$ hold diploma , $10 \%$ hold certificates and only $10 \%$ have gone up to secondary level.

Table 13. Respondents according to their job titles

\begin{tabular}{|l|c|}
\hline Job Title & Number of staff \\
\hline Headmistress/Manager (Interviewee) & 1 \\
\hline Deputy Head & 1 \\
\hline Senior Teacher & 1 \\
\hline Teachers & 17 \\
\hline Sports Coordinator & 1 \\
\hline Swimming Instructor Assistant & 1 \\
\hline Messenger & 1 \\
\hline School Driver & 1 \\
\hline Office Administrator & 1 \\
\hline Public Relations Officer & 1 \\
\hline Bursar & 1 \\
\hline Computer Programmer & 1 \\
\hline School Nurse & 1 \\
\hline Maintenance Officer & 1 \\
\hline Cleaner & 1 \\
\hline Total & 1 \\
\hline respondents accordting their & 1 \\
\hline
\end{tabular}

This shows the distribution of respondents according to their job positions, 9.6\% came from senior management, a $54.8 \%$ came from the teaching staff and $35.4 \%$ came from the school support staff. 


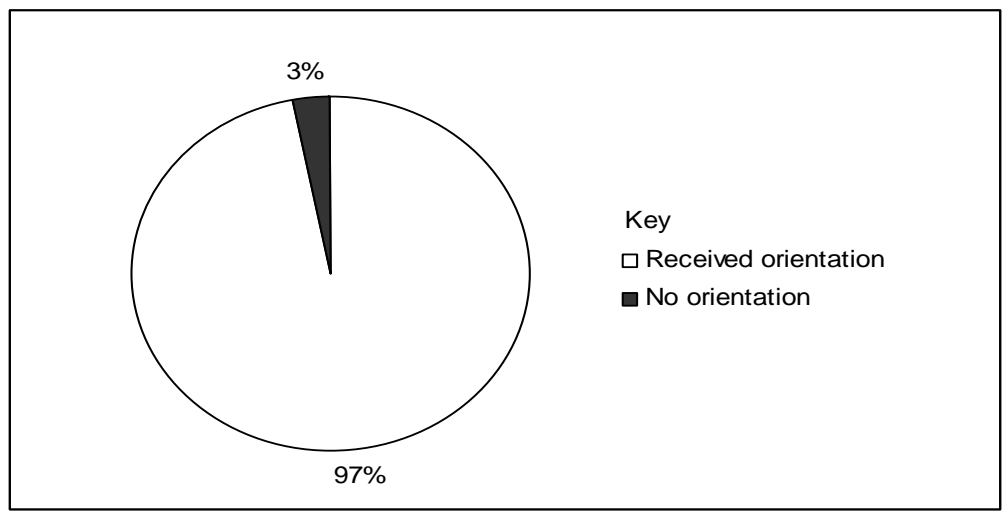

Figure 1. Staff Orientation

According to the findings, $97 \%$ of the respondents said that they were given orientation when they joined the Star Learning Centre; $3 \%$ of the respondents indicated the contrary. The manager, also acknowledged that orientation was an on - going exercise in the Star Learning Centre.

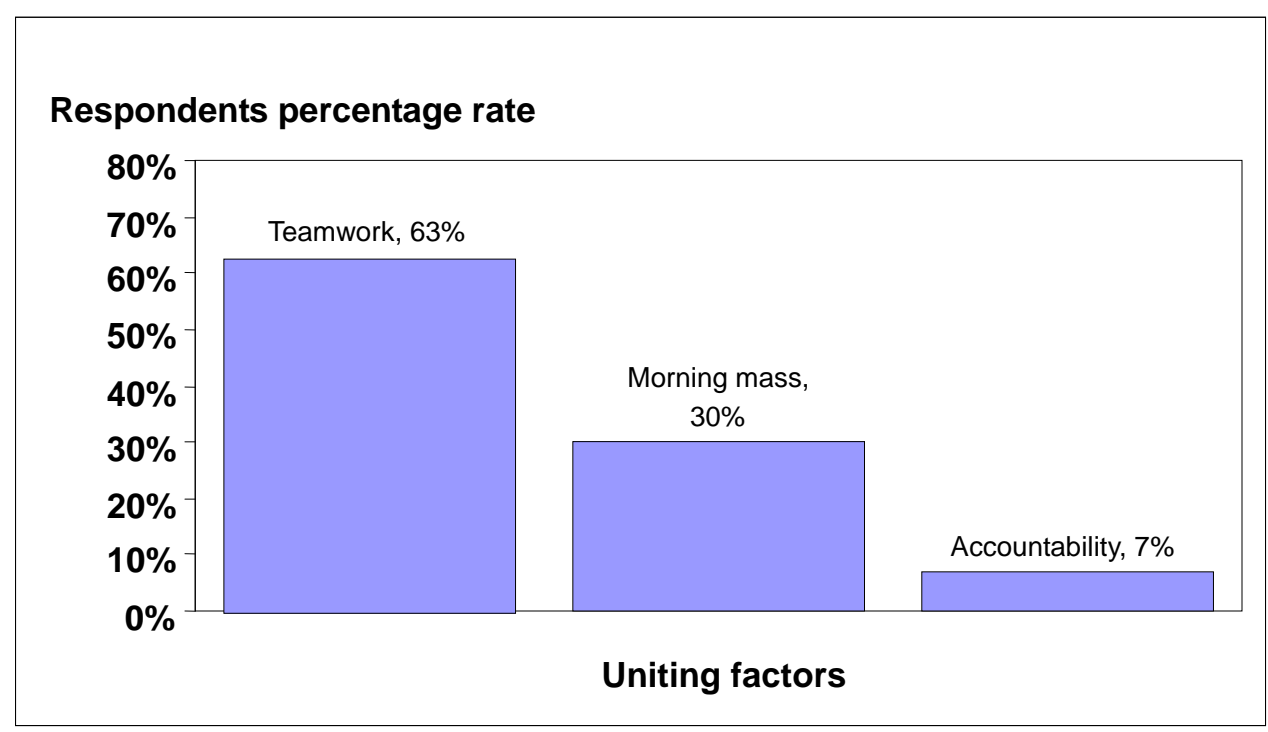

Figure 2. Uniting factor among Star Learning Centre staff

Findings revealed that, $63 \%$ of the respondents reported that the greatest uniting factor among Star Learning Centre staff is teamwork, $30 \%$ said it is daily morning mass in the school chapel and $7 \%$ cited accountability as the greatest uniting factor. 


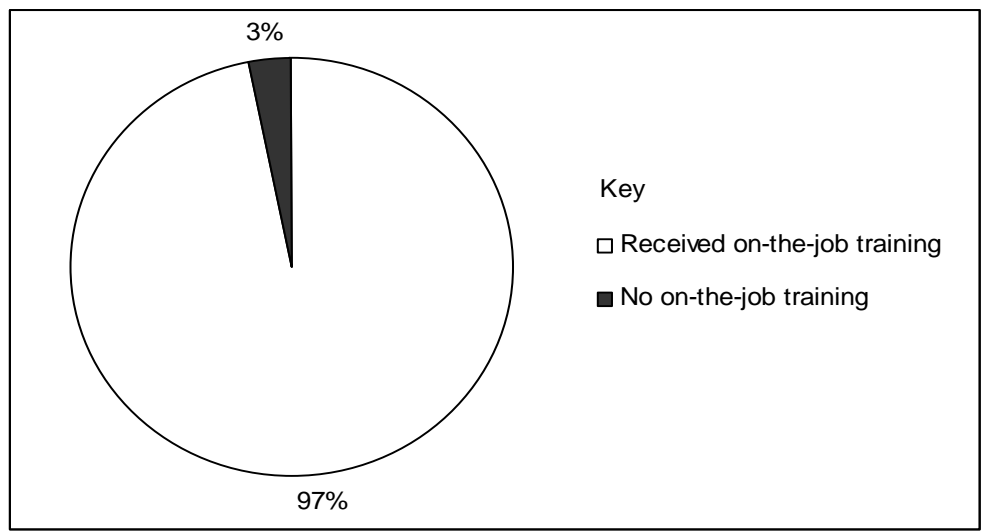

Figure 3. On- the-Job training

From the findings, $97 \%$ of the respondents indicated that they had received on-the-job training since they joined the Star Learning Centre. Only 3\% of the respondents reported not having undergone any on-the-job training since joining Star Learning Centre. The manager also acknowledged the existence of the on-the-job training at the Centre, which is conducted mostly through school based workshops.

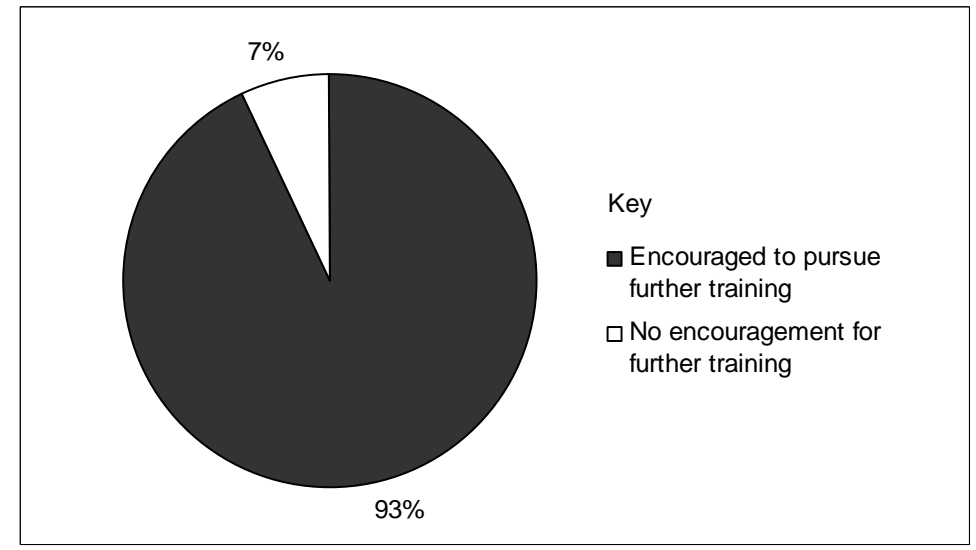

Figure 4. Further Training

According to the findings, 93\% of the respondents indicated that Star Learning Centre management encourages the staff to pursue further studies, $7 \%$ indicated the contrary. 


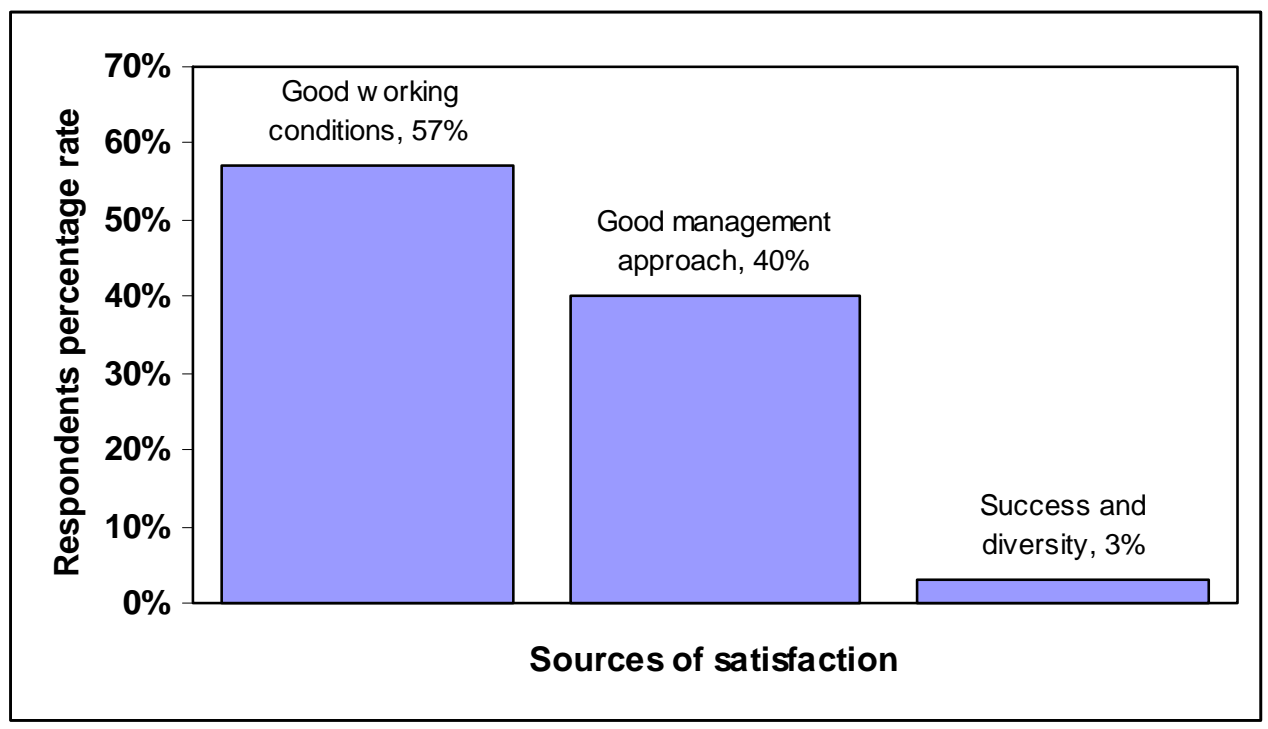

Figure 5. Source of satisfaction to employees of Star Learning Centre

According to the findings, 57\% of the respondents indicated the source of satisfaction for Star Learning Centre employees as being good working conditions, $40 \%$ good management approach and $3 \%$ the success of the organization and diversity among the staff. The manager said that the Centre's employees could also be deriving joy and motivation from other fringe benefits provided by the management such as free 10 o'clock tea, house allowance and some school organized trips.

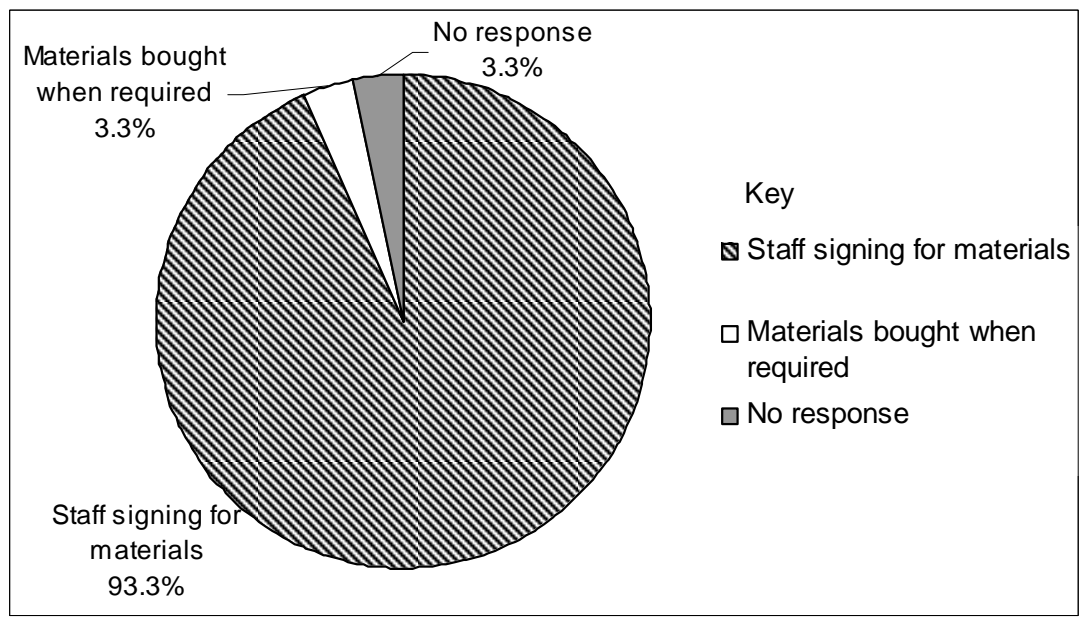

Figure 6. Control of Materials

About 93.3\% of the respondents reported that the material usage in the Star Learning Centre is controlled by staff signing for them at the supplies office, 3.3\% of the respondents reported that it is bought when required and another $3.3 \%$ of the respondents did not give any responses. 


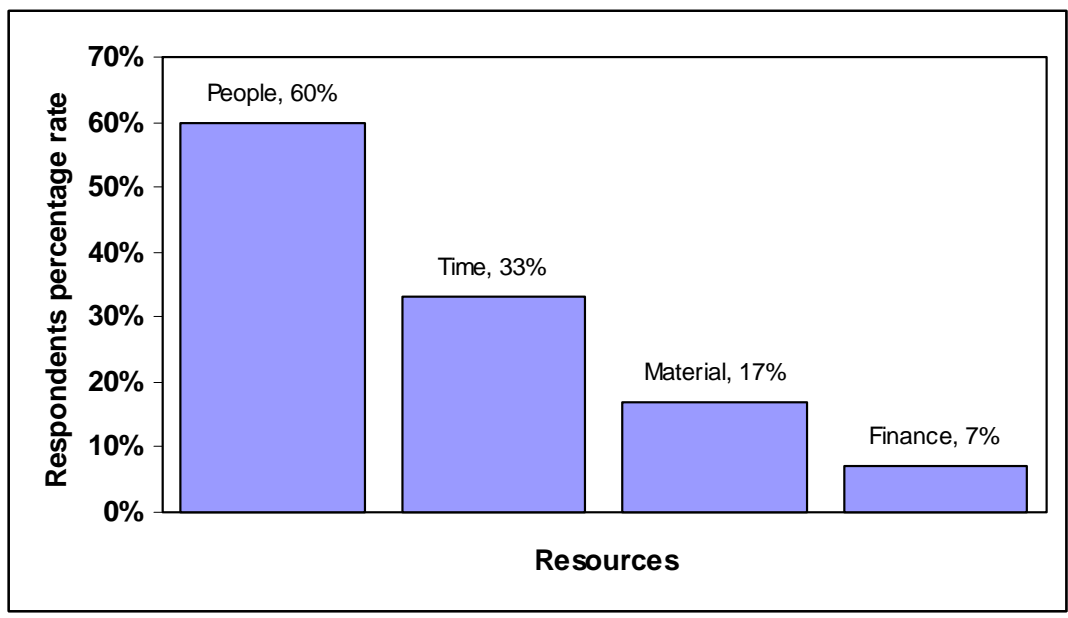

Figure 7. Rating of Management of Resources

According to the findings, $60 \%$ of the respondents indicated that the best managed resource are people, $33 \%$ of the respondents said time, and 17\% materials and 7\% finance. In this question 5 respondents gave each two answers.

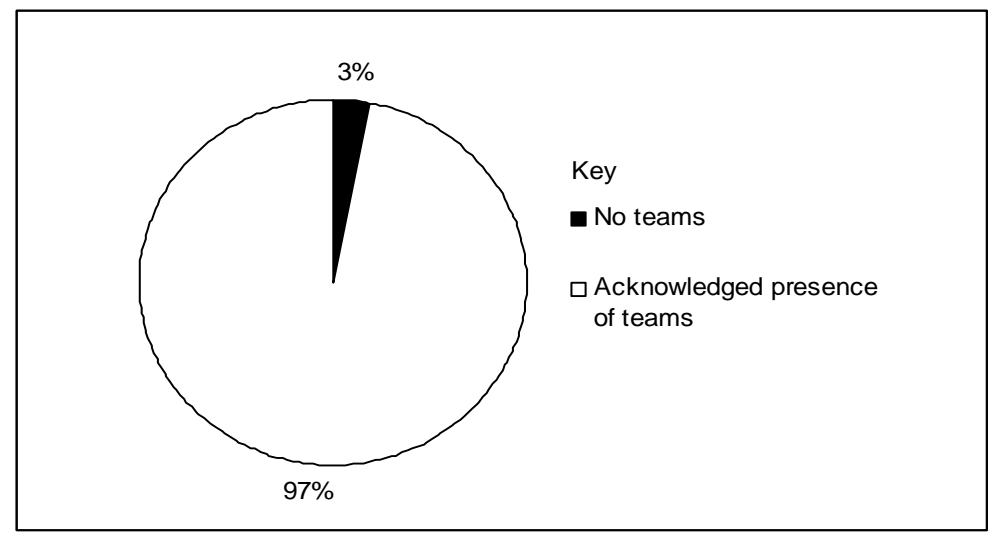

Figure 8. Teams/Committees at Star Learning Centre

According to the findings, $97 \%$ of the respondents indicated that there are teams operating at the Star Learning Centre while $3 \%$ indicated the contrary.

The manager acknowledged presence of teams in the Centre, which are allocated tasks and said this has helped develop a sense of responsibility and accountability among the staff. She said senior teachers are responsible for coordinating team activities. 


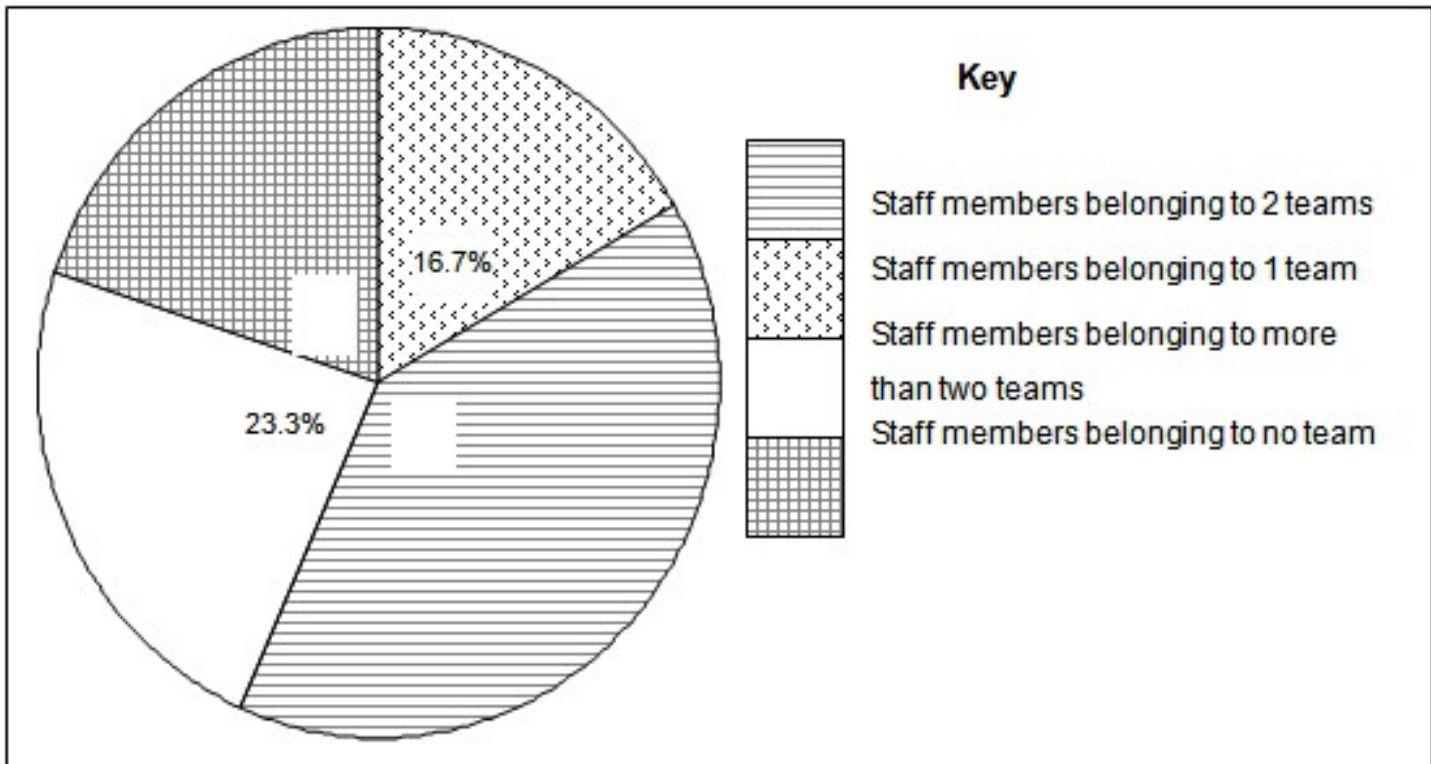

Figure 9. Respondents according to Team Membership

According to the findings, $40 \%$ of the respondents belonged to two teams, $23.3 \%$ belong to more than two; and $20 \%$ indicated that they do not belong to any team/ committee in the Star Learning Centre; and $16.7 \%$ of the respondents indicated that they belong to one team/committee.

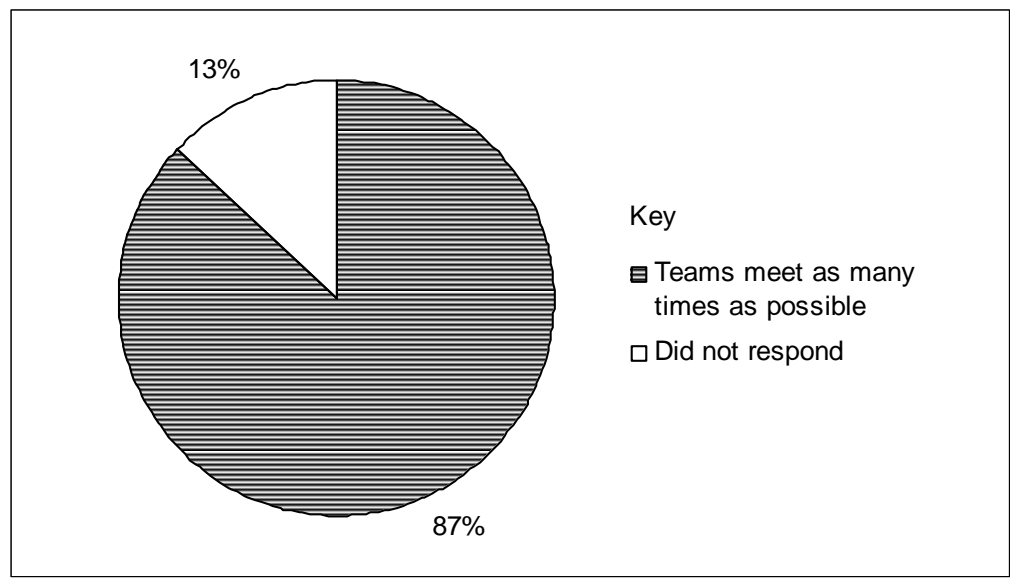

Figure 10. Number of times teams meet

According to the findings, $40 \%$ of the respondents belonged to two teams, $23.3 \%$ belong to more than two; and $20 \%$ indicated that they do not belong to any team/ committee in the Star Learning Centre; and $16.7 \%$ of the respondents indicated that they belong to one team/committee. 


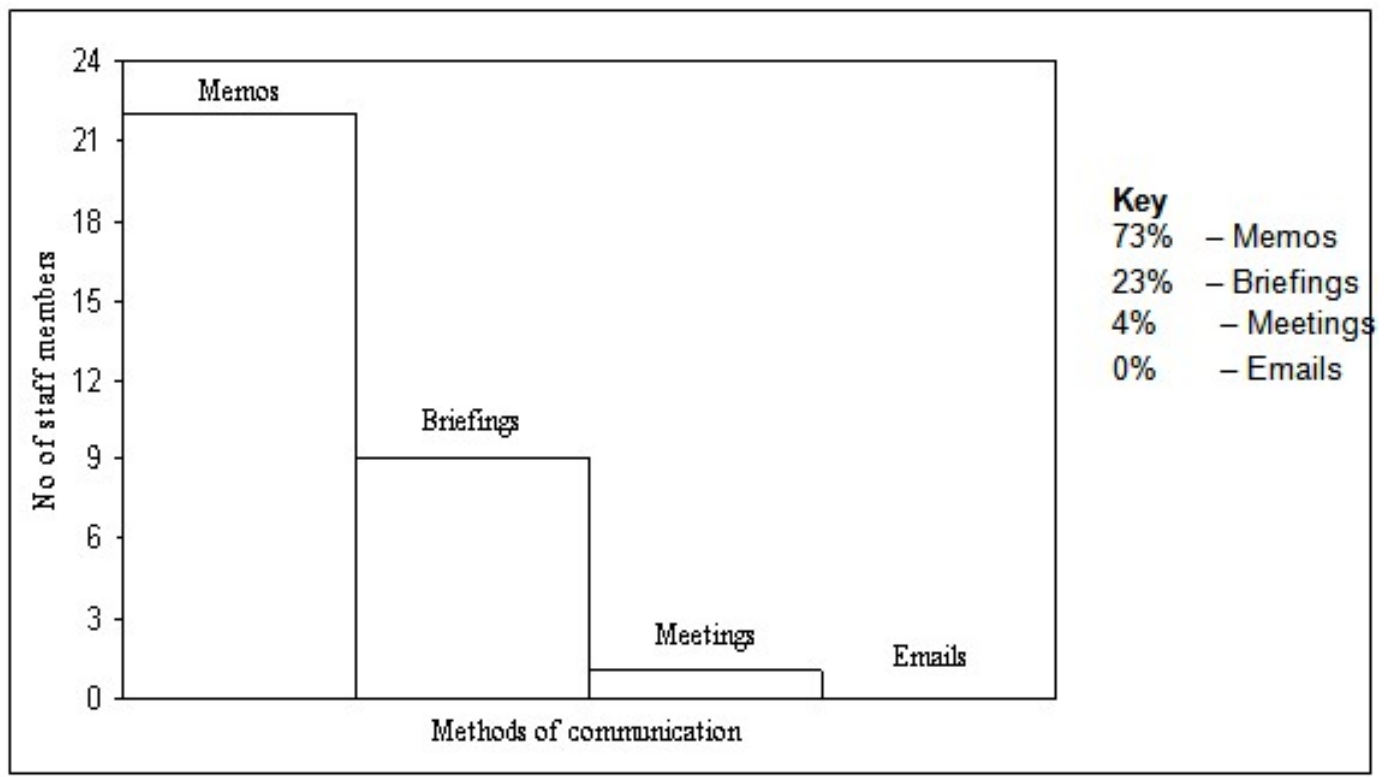

Figure 11. Common methods of communication in Star Learning Centre

According to the findings $73 \%$ of the respondents, cited the memorandum as the most commonly used method of communication at the Star Learning Centre, 23\% of the respondents said briefings and $4 \%$ cited memorandum and briefings.

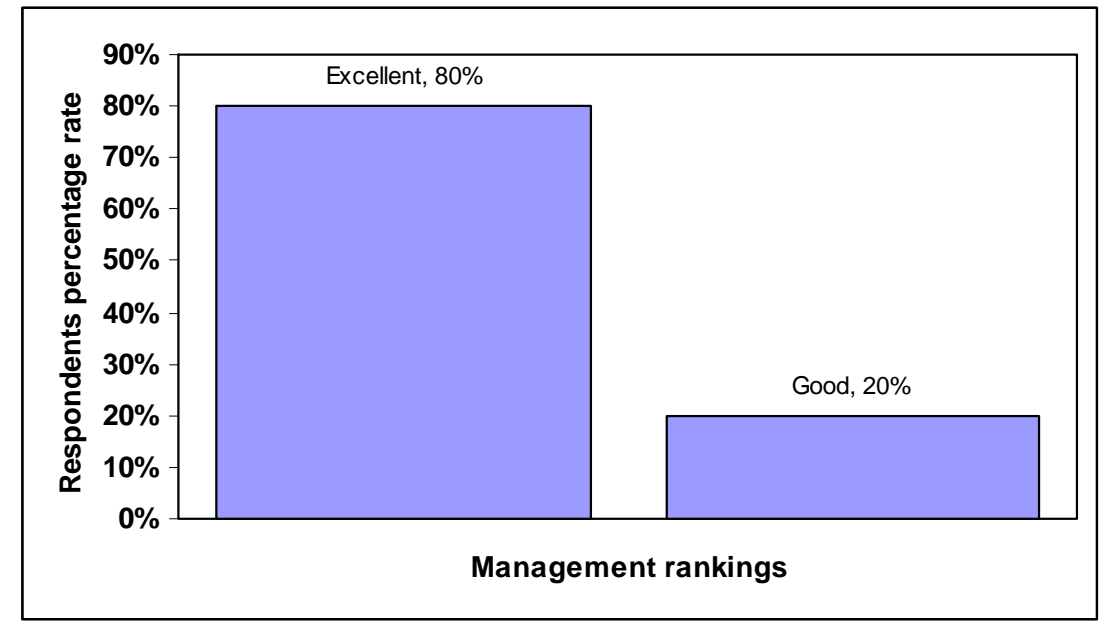

Figure 12. Rating of Management

According to the findings, $80 \%$ of the respondents ranked Star Learning Centre management as excellent while 20\% ranked it as good. 


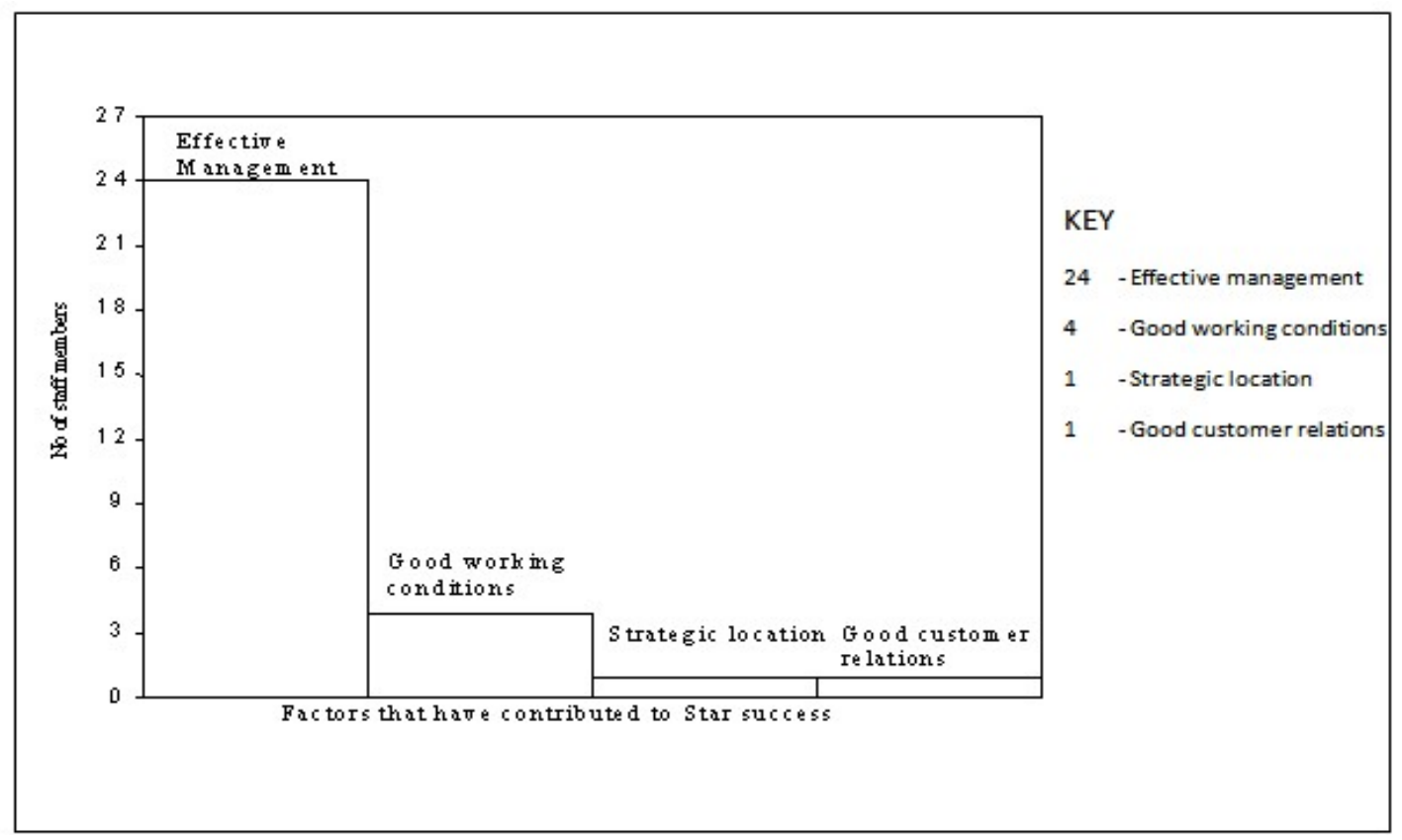

Figure 13. Factors that have contributed to the success of Star Learning Centre

Findings revealed that, $80 \%$ of the respondents cited the success of Star as largely being attributed to effective management, $13.3 \%$ recorded good working conditions, 3.3\% recorded the strategic location and 3.3\% recorded good customer relations.

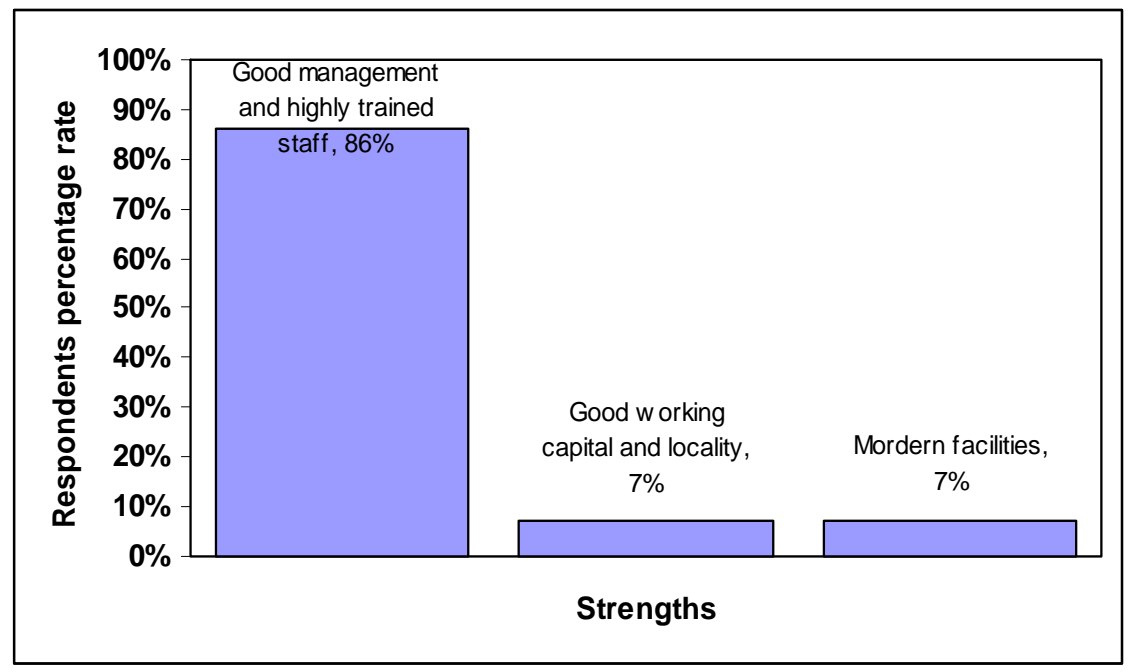

Figure 14. Most outstanding strength of the Star Learning Centre

According to the findings, $86 \%$ of the respondents cited that good management and highly trained staff the most outstanding strengths of Star Learning Centre; 7\% cited good working capital and locality; and 7\% cited legality and modern facilities. 


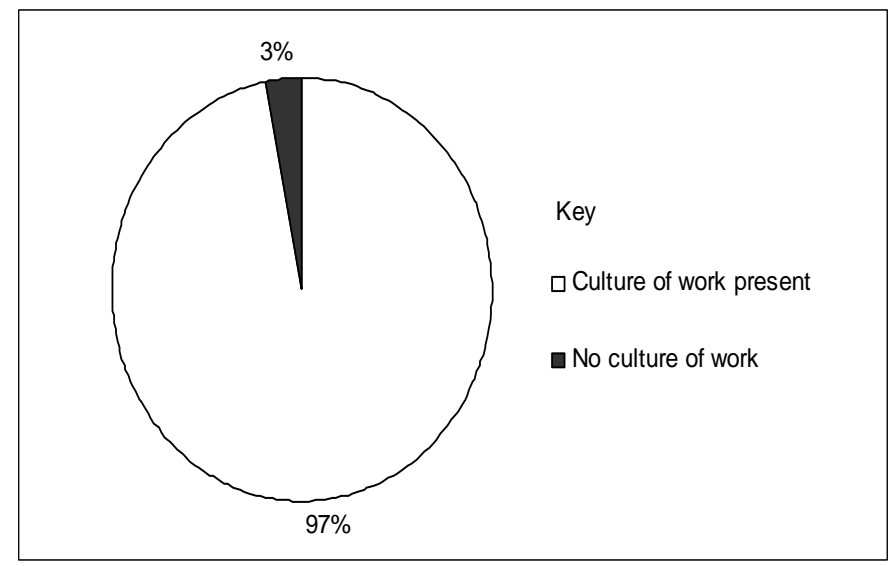

Figure 15. Culture of Work at Star Learning Centre

A large number of the respondents (97\%) recorded that there is a culture of teamwork at Star Learning Centre and 3\% indicated the opposite. The manager confirmed the centre's culture of work, as that of teamwork, achievement and hard work. She explained that values such as: good moral conduct, hard work, teamwork, good customer service, achievement among others, which are observed by all staff, forms part of the Centre’s culture.

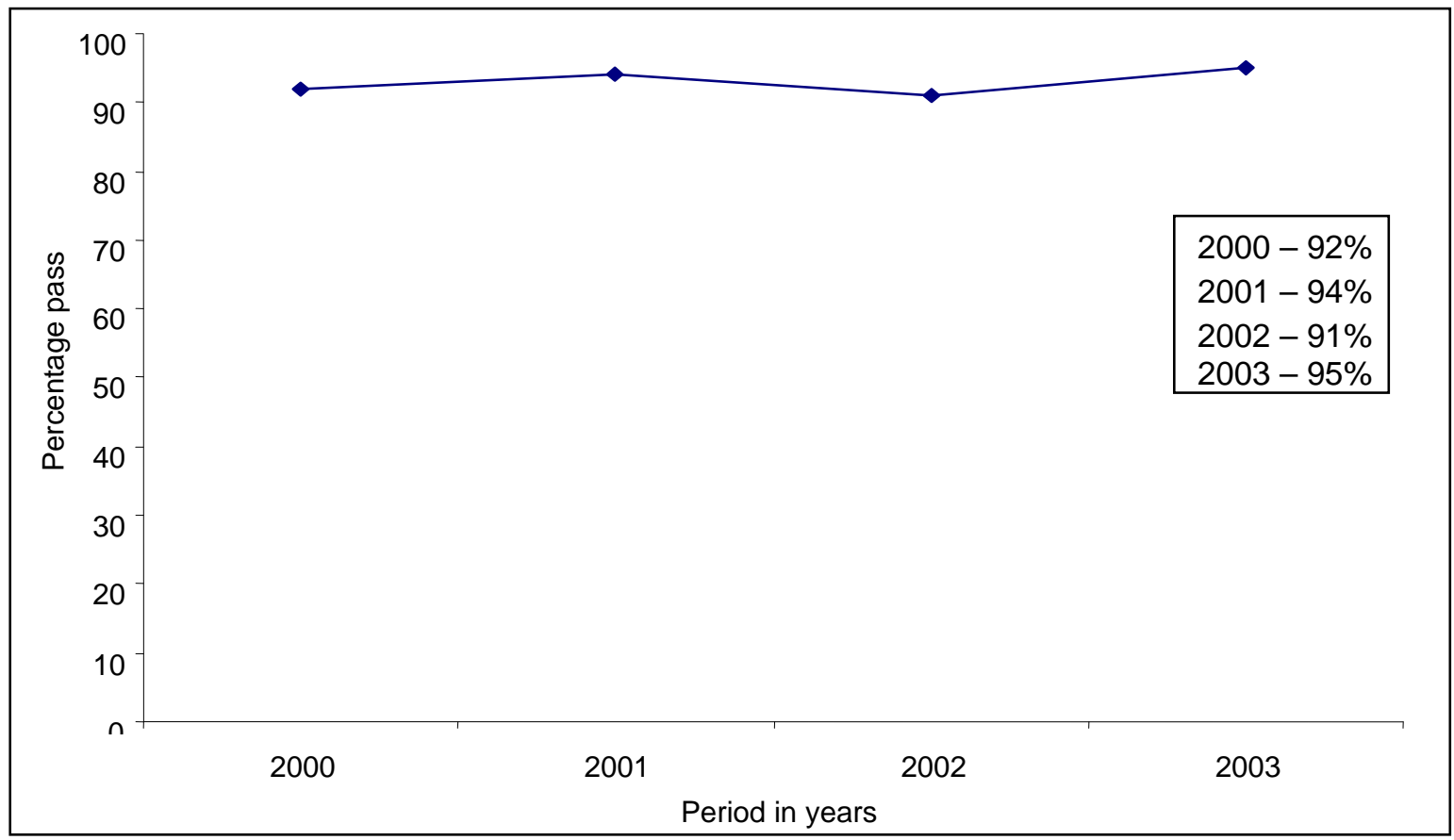

Figure 16. Star Learning Centre PSLE Results Trend

The Centre's manager acknowledged that the most outstanding achievement of the Star Learning Centre are the Primary School Leaving Examination results which were recorded as 92\% in 2000, 94\% in 2001, 91\% in 2002 and 95\% in 2003 pass. 